\title{
Watercraft Decontamination Practices to Reduce the Viability of Aquatic Invasive Species Implicated in Overland Transport.
}

Shrisha Mohit ( $\square$ shrisha.mohit@queensu.ca )

Queen's University https://orcid.org/0000-0002-5391-7328

Timothy B. Johnson

Ontario Ministry of Natural Resources and Forestry

Shelley E. Arnott

Queen's University

\section{Research Article}

Keywords: Recreational watercraft, aquatic invasive species, overland dispersal, secondary spread, decontamination, clean drain dry

Posted Date: November 10th, 2021

DOI: https://doi.org/10.21203/rs.3.rs-1021628/v1

License: (c) (i) This work is licensed under a Creative Commons Attribution 4.0 International License. Read Full License 
Watercraft decontamination practices to reduce the viability of aquatic invasive species implicated in overland transport.

5 Shrisha Mohit ${ }^{1 *}$, Timothy B. Johnson ${ }^{2}$, Shelley E. Arnott ${ }^{1}$

${ }^{1}$ Queens University, Department of Biology, 116 Barrie Street, Kingston, ON, Canada, K7L 3N6

${ }^{2}$ Ontario Ministry of Northern Development, Mines, Natural Resources, and Forestry, Glenora Fisheries Station,

Picton, ON, Canada, K0K 2T0

10

* Corresponding author email: shrisha.mohit@queensu.ca 


\begin{abstract}
Recreational boating activities enable aquatic invasive species (AIS) dispersal among disconnected lakes, as

15 invertebrates and plants caught on or contained within watercraft and equipment used in invaded waterbodies can survive overland transport. Resource management agencies worldwide recommend decontaminating watercraft and equipment using high water pressure, rinsing with hot water, or air-drying for up to seven days to inhibit this mode of secondary spread. There is a lack of studies on the efficacy of these methods under realistic conditions and considering feasibility for recreational boaters. Hence, we conducted experiments addressing this knowledge gap using AIS present in Ontario, namely zebra mussels (Dreissena polymorpha), banded mystery snails (Viviparus georgianus), spiny waterfleas (Bythotrephes cederstroemi), Eurasian watermilfoil (Myriophyllum spicatum), Carolina fanwort (Cabomba caroliniana), and European frogbit (Hydrocharis morsus-ranae). Washing at high pressures of 900-1200 psi removed the most biological material (90\%) from surfaces. Brief (<10s) exposure to water at $\geq 60^{\circ} \mathrm{C}$ caused nearly $100 \%$ mortality among all species tested, except snails. Acclimation to temperatures from

$2515^{\circ} \mathrm{C}$ to $30^{\circ} \mathrm{C}$ before hot water exposure had little effect on the minimum temperature required for no survival. Airdrying durations producing complete mortality were $\geq 60 \mathrm{~h}$ for zebra mussels and spiny waterfleas, and $\geq 6$ days among plants, whereas survival remained high among snails after a week of air-drying. Hot water exposure followed by air-drying was more effective than either method separately against all species tested, reducing either the minimum water temperature or air-drying duration necessary. These findings can inform best management strategies
\end{abstract} 30 against AIS spread.

Keywords: Recreational watercraft; aquatic invasive species; overland dispersal; secondary spread; decontamination; clean drain dry. 


\section{Acknowledgments}

Queen's University and the Queen's University Biological Station are situated on traditional Anishinaabe and Haudenosaunee Territory. We would like to acknowledge the lands and lakes where we have had the opportunity to study and learn, and recognize the precolonial history of this land and the peoples who lived here and continue to live here. The authors thank Jeff Brinsmead (Ontario Ministry of Northern Development, Mines, Natural Resources, and Forestry), Francine MacDonald (OMNDMNRF), and Dr. Jaclyn Hill (Fisheries and Oceans Canada) for their support in the collection of invasive species used in this study. We gratefully acknowledge Emily Pope's contribution through data collection for the acclimation experiments, Xinyu Sun, Shuhong Shi, and lab volunteers for assisting with field experiments, and the Queen's University Biological Station for the necessary facilities. We also thank the reviewers of this manuscript for their insights.

\section{Funding}

This study is funded by the Ontario Ministry of Northern Development, Mines, Natural Resources, and Forestry, Canada. Funding was also provided through the Craigie Fellowship, and Senator Frank Carrel Fellowship to SM, and a Natural Sciences and Engineering Research Council of Canada - Undergraduate Student Research Award, and J. Allen Keast Lake Opinicon Undergraduate Research Fellowship to Emily Pope.

\section{Conflict of interest/competing interests}

The authors declare no conflicts of interest.

\section{Availability of data and material / Code availability}

Data and the code (R Statistical Software) for all statistical analyses are available through the Queen's University

55 Dataverse repository.

\section{Authors' contributions}

All authors contributed to the study conception and design. Material preparation, data collection and analysis were performed by Shrisha Mohit, Timothy Johnson and Shelley Arnott. The first draft of the manuscript was written by Shrisha Mohit and all authors commented on and edited previous versions of the manuscript. All authors read and approved the final manuscript. 


\section{Introduction}

Invasive species have been introduced to aquatic ecosystems through various pathways, such as the discharge of ballast waters, the release or escape of species intended for the aquarium or water garden trade and live food market, the use and transport of live baits, as well as the movement of watercraft among disconnected waterbodies (Ricciardi 2007, Vander Zanden and Olden 2008, Drake et al. 2017). There is ample evidence that recreational boating activities are associated with the secondary spread of aquatic invasive species (AIS) among lakes, as the transport of boats and other equipment enable these species to overcome land barriers (Johnson et al. 2001, Leung et al. 2006, De Ventura et al. 2016). Recreational boats and gear used in infested waters are apt to catch or trap plant and invertebrate AIS on various structures such as boat trailers, ropes, anchors, anchor lines and nets, or in compartments that may retain water such as bilge and live wells (Johnson et al. 2001, Bacela-Spychalska et al. 2013, Kelly et al. 2013, Kerfoot et al. 2016). Unless they are removed, these AIS may survive overland transport (Alonso et al. 2016, Collas et al. 2018), whether in humid areas such as the bilge, live wells, and bait buckets, among macrophytes or sediments attached to boats and trailers (Ricciardi et al. 1995, Johnson et al. 2001, Havel 2011, Kelly et al. 2013), or owing to physiologic or metabolic abilities to tolerate conditions outside of water, until

75 they are reintroduced into an aquatic environment (Ricciardi and Rasmussen 1998, Bailey et al. 2004, Havel 2011, Gaff and Oliver 2013). Hence, recreational watercraft and equipment can become the vector for secondary spread of AIS to disconnected lakes and other water bodies (Vander Zanden and Olden 2008). With recreational boaters and lake users moving greater distances and more frequently among water bodies during peak seasons, there are potentially more occasions where AIS propagules are introduced to new environments in this manner (Rothlisberger et al. 2010, Chivers and Leung 2012, Kelly et al. 2013, Drake 2017, Hunt et al. 2019). It is therefore crucial to reduce the number of live or viable AIS propagules arriving at non-colonised sites to prevent their establishment and range expansion (Blackburn et al. 2015, Sinclair and Arnott 2016, 2017).

To prevent the spread of AIS, numerous resource management agencies recommend that recreational boaters adopt practices to clean, drain, and dry watercraft and equipment before transport and use at another site

85 (Mohit et al. 2021, Canadian Council on Invasive Species 2021). For instance, in Ontario, the methods prescribed by the Ministry of Northern Development, Mines, Natural Resources and Forestry include washing with water at a pressure of $250 \mathrm{psi}$, rinsing with hot water at greater than $50^{\circ} \mathrm{C}$, or allowing all parts to airdry for two to seven days (Ontario Ministry of Natural Resources and Forestry 2017). The effect of similar and commonly recommended 
decontamination methods for recreational watercraft and equipment on different AIS have been previously studied, but there is no clear consensus for a broad-spectrum method that could be easily implemented by recreational boaters (Mohit et al. 2021). While air-drying was extensively studied, experiments on hot water use varied largely with regards to the application method and species assessed, whereas few studies evaluated pressure-washing and the use of cleaning products.

In general, increasing air-drying duration was associated with lower survival among various species.

95 Although some AIS exhibited high mortality after air-drying for up to 7 days, others survived air-drying periods lasting weeks to months (Collas et al. 2014, Anderson et al. 2015, Mohit et al. 2021). Alarmingly, over $90 \%$ of all air-drying studies were conducted under laboratory conditions, which may not accurately simulate the environmental variability that boaters would encounter when air-drying their boats and equipment over the span of several days (Mohit et al. 2021). Past studies have also found that hot water immersion at $50^{\circ} \mathrm{C}$ for $>15$ minutes

100 resulted in total mortality among many species (Beyer et al. 2011, Anderson et al. 2015, Shannon et al. 2018, Coughlan et al. 2019). Similar results could be achieved with shorter exposure duration but only if higher water temperatures were used, such as hot water sprays at $60^{\circ} \mathrm{C}$, or steam sprays $\left(\geq 100^{\circ} \mathrm{C}\right)$ (Morse 2009 , Comeau et al. 2011, Coughlan et al. 2019, Crane et al. 2019). Despite evidence that hot water could be an effective decontamination tool, its application requires specific equipment capable of delivering and sustaining high water 105 temperatures. Moreover, no study to date has assessed the effect of hot water on aquatic invasive snails, despite the latter's known tolerance to other decontamination methods (Mohit et al. 2021). Pressure-washing was among the less well-studied methods. Previous experiments assessing the efficacy of pressurised hot water (Morse 2009, Bradbeer et al. 2021) did not include comparison groups testing different pressures, but rather, they primarily evaluated different water temperatures. However, studies by Rothlisberger et al. (2010) and Wong et al. (2014)

110 evaluated the efficacy of pressure itself, comparing high and low water pressure groups. Rothlisberger et al. reported that 1800 psi removed significantly more entangled plants and small organisms than 40 psi, while Wong et al. demonstrated that 3000 psi removed dreissenid mussels from heavily encrusted surfaces faster than 1500 psi. Nevertheless, neither tested a range of pressures and, considering the variation in pressure output of commerciallyavailable power-washers, the efficacy of this method is thus not well understood. There is also a lack of research on 115 the effects of implementing multiple means of decontamination sequentially or simultaneously. It is unknown whether combining different decontamination methods can improve efficacy, or if their performance differs across 
various species under the same conditions. In addition, no study so far seems to have assessed whether the response of AIS to prescribed decontamination methods is affected by acclimation to the changing environmental conditions over the span of a boating season. Previous research has shown that cold-acclimated invasive apple snails were more resistant to desiccation (Wada and Matsukura 2011), and invasive marine macrophytes were more resilient than native species after exposure to heat stress if they had been previously acclimated to warmer conditions (Atkinson et al. 2020).

Informed by the gaps in knowledge identified in the literature and considering environmental and logistic factors that recreational boaters may encounter when decontaminating boats and equipment, we performed a series

125 of experiments to test the efficacy of pressure washing, brief hot water exposure, air-drying under outdoor conditions, and the combination of hot water exposure followed by air-drying. Our pressure washing experiments on periphyton and plant fragments tested pressures ranging from the equivalent of no washing to those that could be generated using commercially-available electric washers. Similarly, the experiments to test the efficacy of air-drying and hot water application were comprised of trials simulating rinsing with hot water and air-drying periods representing realistic durations between watercraft and equipment use at different sites. We designed experiments with hot water exposure followed by air-drying to determine if combining decontamination methods could have an additive or synergistic effect on efficacy. These experiments were conducted on three invertebrate and three plant AIS present in Ontario to identify conditions that would be the most effective against diverse species. We also assessed whether acclimation to different water temperatures affected the viability of AIS subjected to the hot water treatment.

\section{Methods}

All experiments were conducted at the Queen's University Biological Station (QUBS; 44.568 N, 76.325 W) from May 22 to August 23, 2019, and at the Queen's University campus (44.225 N, 76.495 W) from October 10 to 17,2019 , in Ontario, Canada.

\section{Pressure-washing experiments}

We tested the efficacy of five water pressures $(50,125,550,900,1950 \mathrm{psi})$ plus a control (0 psi) to remove a known amount of material at a fixed $30 \mathrm{~cm}$ distance from the treated surface. We used a garden hose fitted with a 
145 spray nozzle to produce the 50 psi pressure, and commercially-available electric pressure-washers (Sun Joe SPX3000 and Sun Joe SPX4600) fitted with $25^{\circ}$ spray tips for the higher pressures. The treated surfaces were $20 \mathrm{~cm}$ by $20 \mathrm{~cm}$ aluminum tiles secured to a metal frame oriented both perpendicular to the ground, and at a $20^{\circ}$ angle to imitate the deadrise angle of boat hulls. The tiles in the 0 psi control group were handled and secured to the frame for the same amount of time as in the treatment groups, but did not undergo any washing. Each treatment (pressure 150 by orientation) was replicated three times.

The first experiment used tiles naturally colonized with periphyton that established over a 3-week period by suspending the tiles from wooden frames at a depth of approximately $1 \mathrm{~m}$ below the surface of Lake Opinicon (44.559 N, 76.327 W; Supplementary Information 1-A). Upon retrieval, the periphyton from twelve random tiles was immediately scraped for later analysis (positive control group). The remaining tiles were randomly allocated to each treatment or control group, with equal numbers on the vertical ( $n=3$ per treatment) and angled $(n=3)$ sides of the washing frame. After pressure-washing, the residual periphyton attached to each tile was scraped and collected, filtered using pre-weighed Whatman Grade 1 qualitative filter papers, and dried at $60^{\circ} \mathrm{C}$ for at least 2 hours until a constant mass was achieved. The dry mass of periphyton per tile, for each treatment group and orientation, was calculated and recorded as the outcome measure for the periphyton experiments. In the second experiment, 15 leaflets of Eurasian watermilfoil (Myriophyllum spicatum) were randomly stuck to each of 12 aluminum tiles per treatment group, using $15 \mathrm{ml}$ of extra-strong water-soluble hair gel (Garnier Fructis Extra Strong Gel 600g) spread uniformly over the surface of the plate, similar to Rothlisberger et al. (2010). Six tiles were randomly allocated to each of the vertical and angled sides of the frame, and we recorded the number of whole leaflets and fragments remaining after washing and handling. Each treatment was replicated four times.

\section{Effects of hot water and/or air-drying on survival or viability}

These experiments were conducted using three species of invertebrates (banded mystery snails, Viviparus georgianus; zebra mussels, Dreissena polymorpha; and spiny waterfleas, Bythotrephes cederstroemi) and three species of aquatic plants (Eurasian watermilfoil; Carolina fanwort, Cabomba caroliniana; and European frogbit, with four replicates. 
Banded mystery snails and zebra mussels were manually collected from rocks and sediment at Lake Opinicon. Medium-sized adult snails (15-20 mm) and zebra mussels of two size classes (8-12 mm and 15-20 mm)

175 were selected. All specimens were kept in flow-through tanks with a direct supply of filtered lake water for five to seven days prior to experiments, and we included only healthy individuals in the trials. Spiny waterfleas collected from Lake Ontario $(44.221 \mathrm{~N}, 76.502 \mathrm{~W})$ with a $50 \mu \mathrm{m}$ tow net were used in the experiments on the same day as collection. Eurasian watermilfoil was collected from Lake Opinicon using a sampling rake, and Carolina fanwort was manually pulled from a headwater stream $(44.526 \mathrm{~N}, 77.898 \mathrm{~W})$ and transported to QUBS in plastic bags within sealed coolers to prevent desiccation and accidental release. We cut $10 \mathrm{~cm}$ fragments along each strand, at least 30 $\mathrm{cm}$ away from the roots and apices, and counted the number of leaflets from each fragment to determine the total per group prior to treatment. None of the fragments had any roots or shoots at this time. European frogbit was collected from roadside ponds near QUBS. Any stolon or root was trimmed to a length of $5 \mathrm{~cm}$ when separating the rosettes. We recorded the number of leaves, roots, stolons, fruits, flowers, and turions per rosette before and after treatment. After each trial, the plant and invertebrate specimens were placed in individual, labelled compartments of clear tackle boxes (or modified centrifuge tubes for spiny waterfleas) that were immersed in tanks or containers of filtered lake water for monitoring. We recorded the number of survivors among banded mystery snails and zebra mussels after $24 \mathrm{~h}$, and among spiny waterfleas after $4 \mathrm{~h}$. Snails were classified as alive if they retracted their body into the shells when stimulated. Inactive specimens were considered alive if (i) the body retracted further when the operculum was tapped, or (ii) there was resistance when the operculum was gently tugged with tweezers. Actively filter-feeding zebra mussels were marked as alive, whereas those that did not retract their siphon or close their valves when touched with a probe were considered dead. If the valves were initially closed, the mussels were deemed to be alive if they reopened during a ten-minute observation period. Spiny waterfleas were considered alive if they were actively swimming after immersion. Inactive individuals were transferred to a Petri dish and observed under a dissecting scope, and the absence of any internal movement confirmed that the specimen was dead.

The tanks for the plant fragments were fitted with two air-bubblers, and we added top and side sources of light, so that the fragments received 12 hours of light daily. The position of the boxes was rotated daily by moving the bottom-most box to the top, to allow for even exposure to light, and the water was changed weekly. We monitored the fragments over a period of 28 days for all experiments ( 21 days for the acclimation experiment), 
of all European frogbit structures present before and after the tests, we included only the number of new leaves and new turions in the final analyses.

\section{$\underline{\text { Hot water exposure only }}$}

We used five water temperatures $\left(25^{\circ} \mathrm{C}, 40^{\circ} \mathrm{C}, 50^{\circ} \mathrm{C}, 60^{\circ} \mathrm{C}\right.$, and $\left.70^{\circ} \mathrm{C}\right)$ and three immersion times simulating rinsing through brief exposure $\left(2 \mathrm{~s}, 5 \mathrm{~s}\right.$, and 10s) for all species, except spiny waterfleas where only $25^{\circ} \mathrm{C}$, $40^{\circ} \mathrm{C}$ and $50^{\circ} \mathrm{C}$ were used due to complete mortality at higher temperatures during screening trials. All specimens were placed in mesh containers that were lowered in a water bath held at the tested water temperature.

We also performed acclimation experiments to determine if AIS survival after hot water exposure was affected by the temperature to which the specimens were initially acclimated. Here, we included only banded mystery snails, large zebra mussels (15-20 mm size class), and Eurasian watermilfoil. Specimens were placed in tanks of filtered lake water which was gradually brought to temperatures of $15^{\circ} \mathrm{C}, 20^{\circ} \mathrm{C}, 25^{\circ} \mathrm{C}$ or $30^{\circ} \mathrm{C}$, and then allowed to acclimate to that temperature for seven days. Due to elevated zebra mussel and banded mystery snail mortality during acclimation at $30^{\circ} \mathrm{C}$, the invertebrates from this group were not included in subsequent trials. Otherwise, specimens from each acclimation group were immersed in water at $25^{\circ} \mathrm{C}, 40^{\circ} \mathrm{C}, 50^{\circ} \mathrm{C}, 60^{\circ} \mathrm{C}$, or $70^{\circ} \mathrm{C}$ for

215 five seconds as previously described.

\section{Air-drying only}

Groups of test organisms (except spiny waterfleas) were allowed to air-dry outdoors, away from direct sunlight and rain inside a screen tent at QUBS, for 1h, 3h, 12h, 1.5 days, 2.5 days, 5 days, and 7 days. We also included additional air-drying durations of 3 and 4 days for banded mystery snails after observing a sharp decline in the number of survivors between 2.5 days and 5 days. Trials with spiny waterfleas were performed in the laboratory at Queen's University, for durations of $1 \mathrm{~h}$ and $3 \mathrm{~h}$, due to complete mortality after $12 \mathrm{~h}$ of air-drying.

\section{$\underline{\text { Hot water and air-drying combination }}$}

To assess the efficacy of sequentially applying two decontamination methods, we immersed the test specimens in hot water $\left(25^{\circ} \mathrm{C}, 40^{\circ} \mathrm{C}, 50^{\circ} \mathrm{C}, 60^{\circ} \mathrm{C}\right.$, and $\left.70^{\circ} \mathrm{C}\right)$ for 5 seconds before immediately allowing them to air-

225 dry outdoors for $3 \mathrm{~h}, 12 \mathrm{~h}, 1.5$ days, 2.5 days, and 5 days. In addition, snails were subjected to 4 days of air-drying after hot water exposure, and spiny waterfleas were only exposed to water at $25^{\circ} \mathrm{C}, 40^{\circ} \mathrm{C}$, and $50^{\circ} \mathrm{C}$, combined with air-drying durations of $1 \mathrm{~h}, 3 \mathrm{~h}$, and $12 \mathrm{~h}$ due to complete mortality at higher water temperatures and longer air-drying durations. 
We applied generalised linear models (GLMs) to analyse the data from all experiments, except those for spiny waterfleas where we used Analyses of Variance (ANOVA) with predictor variables as factors, as there were fewer treatment groups. We determined the best data distribution for all experiments by examining the diagnostic plots residuals, and the best models using Aikaike's Information Criteria (AIC) values, or quasi-AIC (qAIC) if there 235 was significant dispersion in the data. All analyses were performed using the statistical software R (version R-3.5.2, R Core Team 2020), and figures were created with the ggplot2 package (Wickham 2016). Table 1 shows the predictor and response variables included for each experiment and study species, and the model comparison and selection are shown in the Supplementary Information $2-A$.

From the pressure washing experiments, we estimated the pressure output required to remove the most

240 periphyton or leaf fragments from surfaces using the best fit regression models for the periphyton and gel experiments respectively. We did not include orientation in the final models for the periphyton experiment as it did not have a statistically significant effect on the amount of periphyton residue.

To determine the relationship between treatment conditions and survival among banded mystery snails and zebra mussels, we analysed the data using GLMs for a binomial distribution (logistic regression). We then used the 245 best fitted regressions models to estimate the conditions that produced 50\%, 90\% and 99\% mortality. The two-way ANOVAs on spiny waterfleas tested both the main effects and interaction of predictor variables. A significance level of 0.05 was used for all tests, and we conducted post-hoc tests (Tukey HSD) to evaluate the difference among levels if a significant interaction or main effects was detected.

We used Poisson regressions to determine the relationship between treatment conditions and growth among plants, post-treatment (Supplementary Information $2-B$ ). We assigned a unique number ("plant ID”) to each group of ten Eurasian watermilfoil and Carolina fanwort fragments, or whole European frogbit rosette, and the analyses were repeated for each plant structure of interest (leaves, roots, branches, and turions). Growth, the response variable (Table 1) used in all analyses, was the difference between the number of a given structure recorded during the last week of monitoring and the minimum count recorded at any week for each unique plant ID, as a quantitative 255 indicator of new growth at the end of the recovery period. The data were transformed by adding 1 to the count 
difference to avoid zero values, and thus meet the assumptions of Poisson regressions. Finally, we used the best fit regression models to estimate treatment conditions that produced counts of less than one as a measure of no new growth at the end of the recovery period.

\section{Results}

Results of pressure-washing experiments

Increasing pressure significantly reduced the dry mass of periphyton remaining on washed surfaces except at the highest pressure tested, where the amount of residue increased compared to lower pressures, regardless of orientation (Figure 2a; Supplementary Information $3-A$ ). Using the best fit regression model, we predicted that a

265 pressure of 921 psi removed the most periphyton from the tiles $(90.6 \%)$. We obtained similar results from the gel experiment; while there was no interaction between orientation and pressure based on the best fitted model, the number of leaves and/or leaf fragments remaining attached significantly decreased as pressure increased, except at the highest pressure of 1950 psi, in both orientation groups (Figure 2b). Orientation also had a significant effect on the number of leaflets remaining, with the vertical surface retaining $36 \%$ more fragments than the angled surface (Supplementary Information $3-A$ ). We determined that a pressure of 1113 psi removed the greatest number of fragments by pressure washing for either the vertical $(89.2 \%)$ or angled surface $(92.0 \%)$.

\section{Results of experiments on invertebrates}

\section{Effects of hot water immersion on invertebrates}

When exposed to hot water, the number of banded mystery snails that survived decreased significantly with either increasing water temperature or increasing exposure duration (Figure 3a, Supplementary Information 3 - B). We also observed a rapid decrease in survival at temperatures $\geq 50^{\circ} \mathrm{C}$ and determined that a minimum water temperature of $65^{\circ} \mathrm{C}, 63^{\circ} \mathrm{C}$, and $59^{\circ} \mathrm{C}$ was required for $99 \%$ mortality when snails are exposed to hot water for $2 \mathrm{~s}$, 5s, and 10s, respectively. From the acclimation experiments where only an exposure of 5s was applied, we found that increasing acclimation temperature produced no statistically significant increase or decrease in snail survival, whereas increasing the water temperature for immersion significantly reduced snail survival (Figure 4a). 
Zebra mussels of both size classes had reduced survival when both water temperature and immersion duration increased, with a rapid decrease following immersion at $40^{\circ} \mathrm{C}$ (Figure $3 \mathrm{a}$ ). Increasing water temperature resulted in significantly fewer small zebra mussels surviving after treatment whereas the effect of immersion duration was not statistically significant (Supplementary Information $3-B$ ), and we predicted that a temperature of approximately $57^{\circ} \mathrm{C}$ is required for $99 \%$ mortality. However, among larger zebra mussels, increasing both water temperature and immersion time significantly reduced survival, with higher temperatures of $58^{\circ} \mathrm{C}(10 \mathrm{~s}), 60^{\circ} \mathrm{C}(5 \mathrm{~s})$, and $61^{\circ} \mathrm{C}(2 \mathrm{~s})$ needed to produce $99 \%$ mortality. Our acclimation experiments on large zebra mussels revealed that increasing acclimation temperature led to significantly higher survival after treatment, as opposed to increasing water temperature which significantly reduced survival, again with a rapid decrease at temperatures above $40^{\circ} \mathrm{C}$ (Figure 4b). Nonetheless, the difference in hot water temperatures required for $99 \%$ mortality differed by $2^{\circ} \mathrm{C}$ at most among the three acclimation groups $\left(50^{\circ} \mathrm{C}, 51^{\circ} \mathrm{C}\right.$, and $52^{\circ} \mathrm{C}$ for the $15^{\circ} \mathrm{C}, 20^{\circ} \mathrm{C}$, and $25^{\circ}$ acclimation groups, respectively), albeit being lower than in the experiment without acclimation.

Spiny waterfleas exposed to hot water did not survive temperatures $\geq 50^{\circ} \mathrm{C}$ and we found only a significant main effect of water temperature on survival (two-way ANOVA, $\mathrm{F}=91.241, \mathrm{df}_{\text {temperature }}=2, \mathrm{df}_{\text {residuals }}=22, \mathrm{p}<0.05$ ). Significantly fewer spiny waterfleas survived after immersion at $50^{\circ} \mathrm{C}$ than at either $25^{\circ} \mathrm{C}$ or $40^{\circ} \mathrm{C}$ (Tukey $\mathrm{HSD}$ adjusted $\mathrm{p}<0.05$ ), whereas there was no statistically significant difference in the number of surviving spiny waterfleas at $25^{\circ} \mathrm{C}$ compared to $40^{\circ} \mathrm{C}$ (Tukey HSD adjusted $\mathrm{p}=0.593$; Figure 5a).

\section{Effects of air-drying on invertebrates}

The number of banded mystery snails surviving decreased significantly as air-drying duration increased (Figure 3b; Supplementary Information $3-B$ ). The rate of decrease in survival was progressively reduced as time increased, but the maximum mortality achieved among banded mystery snails was $48.2 \%$, which would result from a minimum air-drying duration of $140 \mathrm{~h}$ based on the best-fitted regression model for our data, where the maximum air-drying duration tested was 7 days. Zebra mussels were more susceptible to air-drying than snails, with some observed differences between the two size classes. Among small zebra mussels, survival was high and variable up to $12 \mathrm{~h}$ of air-drying, but then dropped rapidly such that no small zebra mussels were alive in the $36 \mathrm{~h}$ group onwards (Supplementary Information $1-B$ ). Our best model for the data revealed no statistically significant decrease in survival with increasing air-drying duration, but these results should be interpreted with caution due to the lack of 
variation in the dataset for air-drying durations $\geq 36 \mathrm{~h}$. Survival among the large zebra mussel size class significantly decreased with prolonged air-drying (Figure 3b), with a minimum of $58 \mathrm{~h}$ required for $99 \%$ mortality.

The results of the one-way ANOVA for spiny waterfleas showed that air-drying duration had a significant effect on the number of spiny waterfleas remaining alive after exposure to air $\left(\mathrm{F}=19.00, \mathrm{df}_{\text {time }}=2, \mathrm{df}_{\text {residuals }}=6, \mathrm{p}=\right.$ 0.003). Significantly fewer spiny waterfleas were alive after $3 \mathrm{~h}$ (Tukey HSD adjusted $\mathrm{p}=0.004$ ) and $12 \mathrm{~h}$ (Tukey HSD adjusted $\mathrm{p}=0.004$ ) of air-drying compared to after $1 \mathrm{~h}$. There was $100 \%$ mortality among spiny waterfleas 315 after $>3 \mathrm{~h}$ of air-drying (Figure $5 b)$.

\section{Effects of combining hot water exposure and air-drying on invertebrates}

When used in combination, increasing both water temperature and air-drying duration resulted in significantly higher snail mortality, with water temperature having a greater effect than drying time (Supplementary Information $3-B)$. As longer air-drying duration resulted in reduced survival for all temperature groups, we predicted that after hot water immersion at $<60^{\circ} \mathrm{C}$, air-drying for $72 \mathrm{~h}\left(25^{\circ} \mathrm{C}\right), 97 \mathrm{~h}\left(40^{\circ} \mathrm{C}\right)$ and $66 \mathrm{~h}\left(50^{\circ} \mathrm{C}\right)$ was needed to produce $50 \%$ mortality (Table 2 ).

We conducted the analyses for both zebra mussel size classes only on data from the $25^{\circ} \mathrm{C}$ and $40^{\circ} \mathrm{C}$ groups as we recorded complete mortality prior to air-drying at water temperatures $\geq 50^{\circ} \mathrm{C}$ in these experiments. Mortality among both large and small mussels was significantly increased by increasing air-drying duration at lower temperatures (Supplementary Information $3-B$ ), with a rapid decrease in survival after air-drying for at least $12 \mathrm{~h}$. We determined that a minimum duration of $27.5 \mathrm{~h}$ and $40.2 \mathrm{~h}$ were required for $99 \%$ mortality among small and large zebra mussels, respectively, following exposure to water temperatures from $25^{\circ} \mathrm{C}$ to $<50^{\circ} \mathrm{C}$.

The results of our two-way ANOVA also showed that spiny waterflea survival was reduced as air-drying duration increased following hot water immersion. We did not detect any significant interaction between water temperature and air-drying time on spiny waterflea survival $\left(\mathrm{F}=1.626, \mathrm{df}_{\text {interaction }}=4, \mathrm{df}_{\text {residuals }}=22, \mathrm{p}=0.203\right)$. However, only the main effect of air-drying duration $\left(\mathrm{F}=8.891, \mathrm{df}_{\text {time }}=2, \mathrm{df}_{\text {residuals }}=24, \mathrm{p}=0.001\right)$, but not water temperature $\left(\mathrm{F}=1.725, \mathrm{df}_{\text {temperature }}=2, \mathrm{df}_{\text {residuals }}=24, \mathrm{p}=0.198\right)$, was statistically significant, and a greater number of spiny waterfleas survived in the group exposed to $1 \mathrm{~h}$ air-drying after hot water immersion, than in the $3 \mathrm{~h}$ and $12 \mathrm{~h}$ groups, where we observed complete mortality (Tukey HSD adjusted $\mathrm{p}=0.004$; Figure $5 \mathrm{c}$ ). 


\section{Results of experiments on macrophytes}

\section{Effects of hot water on macrophytes}

Our results revealed that among the three aquatic plant species tested, increasing water temperature significantly decreased new leaf, root, branch or turion growth (Supplementary Information $3-C$ ). Although the

340 selected models indicate that root growth in Carolina fanwort and turion production in European frogbit was negatively associated with immersion time, this effect was not statistically significant. In general, there was a steady decline in the emergence of new structures with exposure to hot water at temperatures $\geq 40^{\circ} \mathrm{C}$ for all species (Figure 7a, Supplementary Information $1-C$ ). We determined that new growth can be prevented by brief exposure to hot water at $58^{\circ} \mathrm{C}$ among Eurasian watermilfoil, $58^{\circ} \mathrm{C}$ to $62^{\circ} \mathrm{C}$ among Carolina fanwort, and $35^{\circ} \mathrm{C}$ to $42^{\circ} \mathrm{C}$ among

345 European frogbit. While the acclimation experiments on Eurasian watermilfoil also showed that increasing hot water temperature significantly decreases growth, interestingly we found a significant inverse relationship between acclimation temperature and leaf growth (Figure 7c), but not root and branch development (Figure 7d). We predicted that minimum temperatures of approximately $63^{\circ} \mathrm{C}$ would be required to prevent new root and branch growth irrespective of acclimation temperature, but higher temperatures close to $70^{\circ} \mathrm{C}$ would prevent new leaf growth among fragments across all acclimation temperatures.

\section{Effects of air-drying on macrophytes}

Increasing air-drying duration significantly decreased production of new structures among all three macrophytes (Figure 7b; Supplementary Information $1-D$ and $3-C$ ). However, tolerance to desiccation differed considerably among the three species tested, with Carolina fanwort requiring higher minimum air-drying durations to prevent new growth (leaf, 147h; root, 153h; branch, 126h) than Eurasian watermilfoil (leaf, 84h; root, 77h; branch, 84h), and with European frogbit being especially susceptible to desiccation (leaf, 1h; turion, 8.9h).

\section{Effects of hot water immersion followed by air-drying on macrophytes}

Combining decontamination methods generally produced a rapid decline in new growth among aquatic macrophytes (Supplementary Information $1-E$ and $3-C$ ). Among Eurasian watermilfoil and Carolina fanwort 
root, and branch growth. Although we also found a statistically significant positive interaction between hot water temperature and air-drying duration among Carolina fanwort, its magnitude was smaller than the significant negative main effects of water temperature and air-drying. Combining the two techniques drastically reduced the air-drying duration required for no growth in Eurasian watermilfoil and Carolina fanwort compared to implementing air-drying only (Table 3).

While neither water temperature nor air-drying duration had a significant effect on new European frogbit leaf growth, our models revealed that new turion growth increased significantly with increasing water temperature but was not affected by air-drying duration. However, the count of new structures was low across all replicates, and we could not accurately predict the conditions required to prevent new growth among European frogbit.

\section{Discussion}

The findings from this study provide support for the use of hot water, air-drying, and pressure washing as decontamination methods for recreational watercraft, as recommended in Ontario and elsewhere. Our experiments were designed to bridge the gap in knowledge identified in the literature (Mohit et al. 2021) and assess the efficacy of decontamination methods that can be easily and safely carried out by recreational boaters. Our results revealed that specific decontamination parameters are required to ensure the effectiveness of these decontamination methods in reducing the viability of aquatic invasive invertebrates or plants that could potentially be transported among lakes.

Two studies that assessed the efficacy of pressure-washing exclusively both demonstrated the efficacy of high pressure ( $\geq 1500 \mathrm{psi}$ ) in removing attached material from surfaces (Rothlisberger et al. 2010, Wong et al. 2014). In their experiment evaluating the time taken for high pressures of 1500 psi and 3000 psi to remove encrusted mussels from boat hulls, Wong et al. (2014) employed pressures which may not be feasibly reproduced by recreational boaters. Rothlisberger et al. (2010) however, also included a low-pressure group (40 psi) and found that high water pressure (1800 psi) removed more attached plant material (83\%) and small organisms (91\%) than 40 psi (macrophytes, 62\%; small organisms, 74\%). By assessing a range of pressures, we determined that moderate water pressures from approximately 900 to 1200 psi, corresponding to the output of light-duty or electrical pressure washers, could effectively eliminate about $90 \%$ of the amount of material attached to surfaces, whereas higher 
pressures did not have better efficacy. This could be explained by the highest pressure in our experiment causing more splash back and redistributing the dislodged material over the surface instead of the water running off as with the lower pressure groups. Nonetheless our study shows that commercially available medium-duty pressure-washers can be effective cleaning tools for recreational boaters.

When using hot water for decontamination - more specifically, brief exposure durations simulating rinsing rather than prolonged immersion - a minimum temperature of $60^{\circ} \mathrm{C}$ was necessary to produce $99 \%$ mortality among small invertebrates and the plant species tested. In contrast, banded mystery snails were more resistant and required higher temperatures of $\geq 65^{\circ} \mathrm{C}$ for complete mortality. We also assessed whether mortality rates would be influenced by seasonal changes in the lake water temperature experienced by the species of interest over the course of a boating season; we found that Eurasian watermilfoil and snails acclimated to cooler waters were more resistant to hot water exposure, in line with previous studies that found cold-acclimated snails to be more tolerant of various stressors (Wada and Matsukura 2011, Yoshida et al. 2014, Tamburi et al. 2018), whereas the opposite was noted among zebra mussels. Nonetheless, the minimum hot water temperature required for complete mortality only differed by

400 approximately $2^{\circ} \mathrm{C}$ among all species tested, suggesting that seasonal adjustments to the minimum water temperature would add unnecessary complexity to decontamination protocols, regardless of lake water temperature.

Overall, the findings of our study revealed that rinsing at a higher water temperature than the commonly recommended $50^{\circ} \mathrm{C}$ is necessary for complete mortality among several aquatic invasive species. However, outdoors watercraft decontamination using water at very high temperatures may not be practical for recreational boaters.

405 Some barriers to implementation include the need for equipment that can consistently heat large volumes of water to high temperatures, heat loss due to environmental conditions and the type of surface being washed potentially reducing the temperature of water being applied (Bradbeer et al. 2021), and the elevated risk for personal injury or damage to equipment at temperatures $>50^{\circ} \mathrm{C}$. Since previous studies on the effect of hot water immersion as a decontamination method have shown that complete mortality occurs when organisms are exposed to water $<50^{\circ} \mathrm{C}$

410 for longer periods than that of rinsing (Beyer et al. 2011, Anderson et al. 2015, Sebire et al. 2018, Shannon et al. 2018, Coughlan et al. 2019, De Stasio et al. 2019), hot water application would nonetheless remain effective to decontaminate smaller equipment that can be immersed, or compartments that can be flooded then drained. 
Our experiments on air-drying provide some support for the recommended durations of two to seven days. Overall, we observed that increasing air-drying duration increases mortality and reduces viability among all aquatic

415 invasive species, in line with previous studies. Air-drying for three days was sufficient for complete mortality among smaller invertebrates such as zebra mussels and spiny waterfleas, and one week of air-drying could ensure that plant fragments are non-viable, despite the minimum duration differing among the plant species that we tested (European frogbit, half day; Eurasian watermilfoil, 3.5 days; Carolina fanwort, 6.5 days). Tolerance to desiccation was especially notable among banded mystery snails which had low mortality for our tested durations, indicating that adults of this species of operculate snails can withstand being out of water for extended periods. The literature shows that aquatic invasive snail survival following air-drying varies considerably among species; for instance, complete mortality occurred among New Zealand mudsnails after 48h of air-drying (Richards et al. 2004, Collas et al. 2014), whereas others such as bladder snails, channeled apple snails, Chinese mystery snails, and island apple snails can survive from 14 to 154 days out of water (Havel 2011, Collas et al. 2014, Yoshida et al. 2014, Bernatis et 425 al. 2016). Similarly, while the macrophytes in our study were not viable after one week of air-drying and species such as least duckweed, water fern, and Canadian waterweed had at least $90 \%$ mortality within one to five hours (Coughlan et al. 2018), others such as parrot's feather and New Zealand pygmyweed are hardier, requiring approximately 9 to 23 days of air-drying for the same mortality rate (Anderson et al. 2015). Hence, despite airdrying seemingly being the easiest means of decontamination to implement, its efficacy cannot be generalised to include all invasive gastropods or plants, and recreational boaters need to be aware of the type of organisms potentially present in the lakes they visit to ensure that the appropriate decontamination measures are applied.

We previously reported that several studies found a difference in air-drying resistance based on the size or life stage of individuals of the same bivalve and gastropod species (Mohit et al. 2021); these support our observations on zebra mussels, where $100 \%$ mortality occurred after a shorter air-drying duration among smaller 435 specimens (16h) compared to larger ones (58h). Combined with our spiny waterflea results, air-drying appears to be effective in killing smaller organisms or younger individuals of certain species, which might otherwise easily escape visual detection. However, larger individuals or organisms appear to be more tolerant of air-drying, and thus manual removal of larger, visible organisms and entangled plant material is recommended before implementing other decontamination techniques. 

than one decontamination method. Although we only tested the efficacy of brief hot water exposure followed by airdrying, we determined that this combination was generally more effective than either method alone. By combining techniques, not only was a shorter air-drying duration generally required to reduce invertebrate survival or plant viability, but lower and more practical temperatures of $40^{\circ} \mathrm{C}$ and $50^{\circ} \mathrm{C}$ were also sufficient to contribute to complete mortality when coupled with air-drying among most species assessed, compared to the minimum of $60^{\circ} \mathrm{C}$ when using hot water alone. The improved efficacy of combining decontamination methods can be especially useful against resilient species such as banded mystery snails. The latter could tolerate temperatures up to $65^{\circ} \mathrm{C}$ or had a mortality rate of less than $50 \%$ after 6 days of air-drying only. However, mortality rates of up to $90 \%$ mortality can be achieved if snails are first exposed to $60^{\circ} \mathrm{C}$ water, followed by 4 days of air-drying. Hence, our results suggest that implementing more than one means of decontamination would be a better approach than relying on only one method. Combining lower water temperatures and shorter air-drying durations for the same effect could be a more readily adopted and feasible option for recreational boaters, potentially reducing the need for specialised equipment and time constraints. This approach could also ensure that more species and individual organisms are killed prior to transport, as fouled watercraft and equipment potentially carry multiple species (Johnson et al. 2001, Rothlisberger

455 et al. 2010, Kelly et al. 2013) differing in resistance to specific decontamination methods. While future studies could empirically assess the efficacy of other treatment combinations, our results suggest that the most effective approach for watercraft decontamination would be to implement more than one technique sequentially, while also considering ease of implementation and effort for recreational boaters. For instance, recreational boaters could first manually remove visible debris, mud, entangled plants and large invertebrates, followed by pressure washing to dislodge and 460 wash off plant fragments, large and small organisms, and other residues. The subsequent use of hot water (whether to rinse entire structures, immerse small objects, or flood compartments) followed by air-drying would be aimed at killing any remaining organisms that may not be readily detected; however, if previous steps have not been implemented, the water temperature and air-drying duration need to be increased in order to also be effective against larger, more resilient invertebrates and macrophyte fragments which would otherwise be less likely present following manual removal and pressure-washing (Figure 16). This series of action could optimise the efficacy of individual decontamination methods, and consequently assist in preventing the secondary spread of aquatic invasive species among lakes by reducing or eliminating viable propagules that could be transported overland. 


\section{References}

Alonso, A., G. Valle-Torres, and P. Castro-Diez. 2016. Survival of an invasive aquatic snail to overland translocation in non-aquatic media: Implications for spreading. Limnologica 57:60-65. https://doi.org/10.1016/j.limno.2016.01.002

Anderson, L., A. Dunn, P. Rosewarne, and P. Stebbing. 2015. Invaders in hot water: a simple decontamination method to prevent the accidental spread of aquatic invasive non-native species. Biological Invasions 17:2287-2297. https://doi.org/10.1007/s10530-015-0875-6

Atkinson, J., N. G. King, S. B. Wilmes, and P. J. Moore. 2020. Summer and winter marine heatwaves favor an invasive over native seaweeds. Journal of Phycology 56:1591-1600. https://doi.org/10.1111/jpy.13051

Bacela-Spychalska, K., M. Grabowski, T. Rewicz, A. Konopacka, and R. Wattier. 2013. The "killer shrimp" Dikerogammarus villosus (Crustacea, Amphipoda) invading Alpine lakes: overland transport by recreational boats and scuba-diving gear as potential entry vectors? Aquatic Conservation-Marine and Freshwater Ecosystems 23:606-618. https://doi.org/10.1002/aqc.2329

Bailey, S. A., I. C. Duggan, C. D. A. Van Overdijk, T. H. Johengen, D. F. Reid, and H. J. MacIsaac. 2004. Salinity tolerance of diapausing eggs of freshwater zooplankton. Freshwater Biology 49:286-295. https://doi.org/10.1111/j.1365-2427.2004.01185.x

Bernatis, J. L., I. J. McGaw, and C. L. Cross. 2016. Abiotic tolerances in different life stages of apple snails Pomacea canaliculata and Pomacea maculata and the implications for distribution. Journal of Shellfish Research 35:1013-1025. https://doi.org/10.2983/035.035.0424

Beyer, J., P. Moy, and B. De Stasio. 2011. Acute upper thermal limits of three aquatic invasive invertebrates: Hot water treatment to prevent upstream transport of invasive species. Environmental Management 47:67-76. https://doi.org/10.1007/s00267-010-9573-4

Blackburn, T. M., J. L. Lockwood, and P. Cassey. 2015. The influence of numbers on invasion success. Molecular Ecology 24:1942-1953. https://doi.org/10.1111/mec.13075 
Bradbeer, S. J., T. Renals, C. Quinn, D. A. Warren, B. Pile, K. Hills, and A. M. Dunn. 2021. The effectiveness of hot water pressurized spray in field conditions to slow the spread of invasive alien species. Management of Biological Invasions 12:125-147. https://doi.org/10.3391/mbi.2021.12.1.09

Canadian Council on Invasive Species. 2021. Clean Drain Dry. https://canadainvasives.ca/programs/clean-drain-dry/ (accessed 10 March 2021).

Chivers, C., and B. Leung. 2012. Predicting invasions: alternative models of human-mediated dispersal and interactions between dispersal network structure and Allee effects. Journal of Applied Ecology 49:11131123. https://doi.org/10.1111/j.1365-2664.2012.02183.x

Collas, F. P. L., A. Y. Karatayev, L. E. Burlakova, and R. S. E. W. Leuven. 2018. Detachment rates of dreissenid mussels after boat hull-mediated overland dispersal. Hydrobiologia 810:77-84. https://doi.org/10.1007/s10750-016-3072-4

Collas, F. P. L., K. R. Koopman, A. J. Hendriks, G. van der Velde, L. N. H. Verbrugge, and R. Leuven. 2014. Effects of desiccation on native and non-native molluscs in rivers. Freshwater Biology 59:41-55. https://doi.org/10.1111/fwb.12244

Comeau, S., S. Rainville, W. Baldwin, E. Austin, S. Gerstenberger, C. Cross, and W. H. Wong. 2011. Susceptibility of quagga mussels (Dreissena rostriformis bugensis) to hot-water sprays as a means of watercraft decontamination. Biofouling 27:267-274. https://doi.org/10.1080/08927014.2011.564275

Coughlan, N. E., R. N. Cuthbert, J. W. E. Dickey, K. Crane, J. M. Caffrey, F. E. Lucy, E. Davis, and J. T. A. Dick. 2019. Better biosecurity: spread-prevention of the invasive Asian clam, Corbicula fluminea (Muller, 1774). Management of Biological Invasions 10:111-126. https://doi.org/10. 3391/mbi.2019.10.1.07

Coughlan, N. E., R. N. Cuthbert, T. C. Kelly, and M. A. K. Jansen. 2018. Parched plants: survival and viability of invasive aquatic macrophytes following exposure to various desiccation regimes. Aquatic Botany 150:9-15. https://doi.org/10.1016/j.aquabot.2018.06.001 
Crane, K., R. N. Cuthbert, J. T. A. Dick, L. Kregting, H. J. MacIsaac, and N. E. Coughlan. 2019. Full steam ahead: direct steam exposure to inhibit spread of invasive aquatic macrophytes. Biological Invasions 21:13111321. https://doi.org/10.1007/s10530-018-1901-2

De Stasio, B. T., C. N. Acy, K. E. Frankel, G. M. Fritz, and S. D. Lawhun. 2019. Tests of disinfection methods for 520 invasive snails and zooplankton: effects of treatment methods and contaminated materials. Lake and Reservoir Management 35:156-166. https://doi.org/10.1080/10402381.2019.1599086

De Ventura, L., N. Weissert, R. Tobias, K. Kopp, and J. Jokela. 2016. Overland transport of recreational boats as a spreading vector of zebra mussel Dreissena polymorpha. Biological Invasions 18:1451-1466. https://doi.org/10.1007/s10530-016-1094-5

Drake, D. A. R. 2017. Overland spread of aquatic invasive species among freshwater ecosystems due to recreational boating in Canada. DFO Canadian Science Advisory Secretariat. Research Document 2017/031. vi + 38 p.

Drake, D. A. R., S. A. Bailey, and N. E. Mandrak. 2017. Ecological risk assessment of recreational boating as a pathway for the secondary spread of aquatic invasive species in the Great Lakes basin. DFO Canadian Science Advisory Secretariat. Research Document 2017/030. v + 85 p.

Gaff, D. F., and M. Oliver. 2013. The evolution of desiccation tolerance in angiosperm plants: a rare yet common phenomenon. Functional Plant Biology 40:315-328. https://doi.org/10.1071/FP12321

Havel, J. E. 2011. Survival of the exotic Chinese mystery snail (Cipangopaludina chinensis malleata) during air exposure and implications for overland dispersal by boats. Hydrobiologia 668:195-202. https://doi.org/10.1007/s10750-010-0566-3

535 Hunt, L. M., D. M. Morris, D. A. R. Drake, J. D. Buckley, and T. B. Johnson. 2019. Predicting spatial patterns of recreational boating to understand potential impacts to fisheries and aquatic ecosystems. Fisheries Research 211:111-120. https://doi.org/10.1016/j.fishres.2018.11.007 
Johnson, L. E., A. Ricciardi, and J. T. Carlton. 2001. Overland dispersal of aquatic invasive species: A risk assessment of transient recreational boating. Ecological Applications 11:1789-1799. https://doi.org/10.1890/1051-0761(2001)011[1789:ODOAIS]2.0.CO;2

Kelly, N. E., K. Wantola, E. Weisz, and N. D. Yan. 2013. Recreational boats as a vector of secondary spread for aquatic invasive species and native crustacean zooplankton. Biological Invasions 15:509-519. https://doi.org/10.1007/s10530-012-0303-0

Kerfoot, W. C., M. M. Hobmeier, F. Yousef, B. M. Lafrancois, R. P. Maki, and J. K. Hirsch. 2016. A plague of waterfleas (Bythotrephes): impacts on microcrustacean community structure, seasonal biomass, and secondary production in a large inland-lake complex. Biological Invasions 48:1121-1145. https://doi.org/10.1007/s10530-015-1050-9

Leung, B., J. M. Bossenbroek, and D. M. Lodge. 2006. Boats, pathways, and aquatic biological invasions: Estimating dispersal potential with gravity models. Biological Invasions 8:241-254. https://doi.org/10.1007/s10530-004-5573-8

Mohit, S., T. B. Johnson, and S. E. Arnott. 2021. Recreational watercraft decontamination: can current recommendations reduce aquatic invasive species spread? Management of Biological Invasions 12:148164. https://doi.org/10. 3391/mbi.2021.12.1.10

Morse, J. T. 2009. Assessing the effects of application time and temperature on the efficacy of hot-water sprays to mitigate fouling by Dreissena polymorpha (zebra mussels Pallas). Biofouling 25:605-610. https://doi.org/10.1080/08927010902989245

Ontario Ministry of Natural Resources and Forestry. 2017. Boater Action Plan. https://files.ontario.ca/boater_action_plan_invasivespecies-2017.pdf (accessed 16 March 2020).

R Core Team. 2020. R: A language and environment for statistical computing. R Foundation for Statistical Computing, Vienna, Austria. https://www.R-project.org/ (accessed 16 March 2020). 
Ricciardi, A. 2007. Are modern biological invasions an unprecedented form of global change? Conservation Biology 21:329-336. https://doi.org/10.1111/j.1523-1739.2006.00615.x

Ricciardi, A., and J. B. Rasmussen. 1998. Predicting the identity and impact of future biological invaders: a priority for aquatic resource management. Canadian Journal of Fisheries and Aquatic Sciences 55:1759-1765. http://dx.doi.org/10.1139/cjfas-55-7-1759

Ricciardi, A., R. Serrouya, and F. G. Whoriskey. 1995. Aerial exposure tolerance of zebra and quagga mussels (Bivalvia: Dreissenidae): implications for overland dispersal. Canadian Journal of Fisheries \& Aquatic Sciences 52:470-477. https://doi.org/10.1139/f95-048

Richards, D. C., P. O'Connell, and D. C. Shinn. 2004. Simple control method to limit the spread of the New Zealand mudsnail Potamopyrgus antipodarum. North American Journal of Fisheries Management 24:114-117. https://doi.org/10.1577/M02-133

Rothlisberger, J. D., W. L. Chadderton, J. McNulty, and D. M. Lodge. 2010. Aquatic invasive species transport via trailered boats: what is being moved, who is moving it, and what can be done. Fisheries 35:121-132. https://doi.org/10.1577/1548-8446-35.3.121

575 Sebire, M., G. Rimmer, R. Hicks, S. J. Parker, and P. D. Stebbing. 2018. A preliminary investigation into biosecurity treatments to manage the invasive killer shrimp (Dikerogammarus villosus). Management of Biological Invasions 9:101-113. https://doi.org/10.3391/mbi.2018.9.2.04

Shannon, C., C. H. Quinn, P. D. Stebbing, C. Hassall, and A. M. Dunn. 2018. The practical application of hot water to reduce the introduction and spread of aquatic invasive alien species. Management of Biological Invasions 9:417-423. https://doi.org/10.3391/mbi.2018.9.4.05

Sinclair, J. S., and S. E. Arnott. 2016. Strength in size not numbers: propagule size more important than number in sexually reproducing populations. Biological Invasions 18:497-505. https://doi.org/10.1007/s10530-015$\underline{1022-0}$ 
Sinclair, J. S., and S. E. Arnott. 2017. Relative importance of colonist quantity, quality, and arrival frequency to the extinction of two zooplankton species. Oecologia 184:441-452. https://doi.org/10.1007/s00442-017-3874-8

Tamburi, N. E., M. E. Seuffert, and P. R. Martin. 2018. Temperature-induced plasticity in morphology and relative shell weight in the invasive apple snail Pomacea canaliculata. Journal of Thermal Biology 74:331-336. https://doi.org/10.1016/j.jtherbio.2018.04.008

Vander Zanden, M. J., and J. D. Olden. 2008. A management framework for preventing the secondary spread of aquatic invasive species. Canadian Journal of Fisheries and Aquatic Sciences 65:1512-1522. https://doi.org/10.1139/F08-099

Wada, T., and K. Matsukura. 2011. Linkage of cold hardiness with desiccation tolerance in the invasive freshwater apple snail, Pomacea canaliculata (Caenogastropoda: Ampullariidae). Journal of Molluscan Studies 77:149-153. https://doi.org/10.1093/mollus/eyq049

595 Wickham, H. 2016. ggplot2: Elegant graphics for data analysis. Springer-Verlag, New York.

Wong, W. H., S. Gerstenberger, and A. Watters. 2014. Using pressurized hot water spray to kill and remove dreissenid mussels on watercraft: Field testing on the efficacy of water temperature, high pressure, and duration of exposure. New York. https://www.oneonta.edu/academics/biofld/PUBS/ANNUAL/2014/28\%20Wong\%20watercraft.pdf

600 Yoshida, K., K. Matsukura, N. J. Cazzaniga, and T. Wada. 2014. Tolerance to low temperature and desiccation in two invasive apple snails, Pomacea canaliculata and P. maculata (Caenogastropoda: Ampullariidae), collected in their original distribution area (northern and central Argentina). Journal of Molluscan Studies 80:62-66. https://doi.org/10.1093/mollus/eyt042 
Table 1. Experimental design for controlled experiments to assess the efficacy of pressure washing, water temperature, air-drying, and their combination on different invasive invertebrates and macrophytes. Table contents identify the predictor and response variables used in the statistical analyses of the results.

610

Table 2. Predicted air-drying time required for 50-99\% banded mystery snail mortality after hot water immersion for $5 \mathrm{~s}$ at temperatures from $25^{\circ} \mathrm{C}$ to $70^{\circ} \mathrm{C}$.

Table 3. Minimum air-drying duration required for no new growth of leaves, roots, and branches of Eurasian 615 watermilfoil and Carolina fanwort without and after hot water exposure. 


\section{Figure captions}

Figure 1. Relationship between amount of material remaining on surfaces and water pressure for a) naturally colonized and b) gel seeded experiments. Jittered points represent the observed data, solid lines and shaded areas indicate regression lines and 95\% confidence bands, respectively. Open black circles correspond to tiles placed vertically or perpendicular to the ground, and blue dots to tiles placed at a $20^{\circ}$ angle to the ground.

Figure 2. Relationship between banded mystery snail and large zebra mussel survival and a) hot water temperature (only results for $5 \mathrm{~s}$ immersion are shown) and b) air-drying duration. Open blue circles and black dots correspond to banded mystery snails and large zebra mussels, respectively.

Figure 3. Relationship between a) banded mystery snail and b) zebra mussel survival and hot water temperature at three acclimation temperatures. Open blue circles, black dots, red triangles correspond to acclimation at $15^{\circ} \mathrm{C}, 20^{\circ} \mathrm{C}$, and $25^{\circ} \mathrm{C}$, respectively.

Figure 4. Spiny waterflea survival at different a) immersion temperatures, b) air-drying durations, and c) combined temperature plus air-drying. Groups sharing the same letter indicators were not significantly different from one another based on pairwise Tukey HSD test. White, light blue, and dark grey boxes correspond to immersion

635 durations of $2 \mathrm{~s}, 5 \mathrm{~s}$, and $10 \mathrm{~s}$, respectively, in panel $a$, and to water temperatures of $25^{\circ} \mathrm{C}, 40^{\circ} \mathrm{C}$, and $50^{\circ} \mathrm{C}$ in panel $c$.

Figure 5. Relationship between new structure growth after 4 weeks (or 3 weeks for acclimation experiment) and a) temperature, b) air-drying, c) and d) temperature following acclimation for the most resistant macrophyte species within each experiment type. Panels $a$ and $b$ (results for Carolina fanwort): open blue circles - number of leaves, black dots - number of roots, and red triangles - number of branches. Panel $c$ (acclimation experiment results for Eurasian watermilfoil): open black circle - acclimation at $15^{\circ} \mathrm{C}$, blue dot - at $20^{\circ} \mathrm{C}$, open purple triangle - at $25^{\circ} \mathrm{C}$, and filled red triangle - at $30^{\circ} \mathrm{C}$. Panel $d$ : open blue circles - number of roots, and black dots - number of branches. 
Figure 6. Potential approaches to the implementation of decontamination methods with good, better, and best 645 efficacy in reducing the number of viable specimens of aquatic invasive species. 
Figures
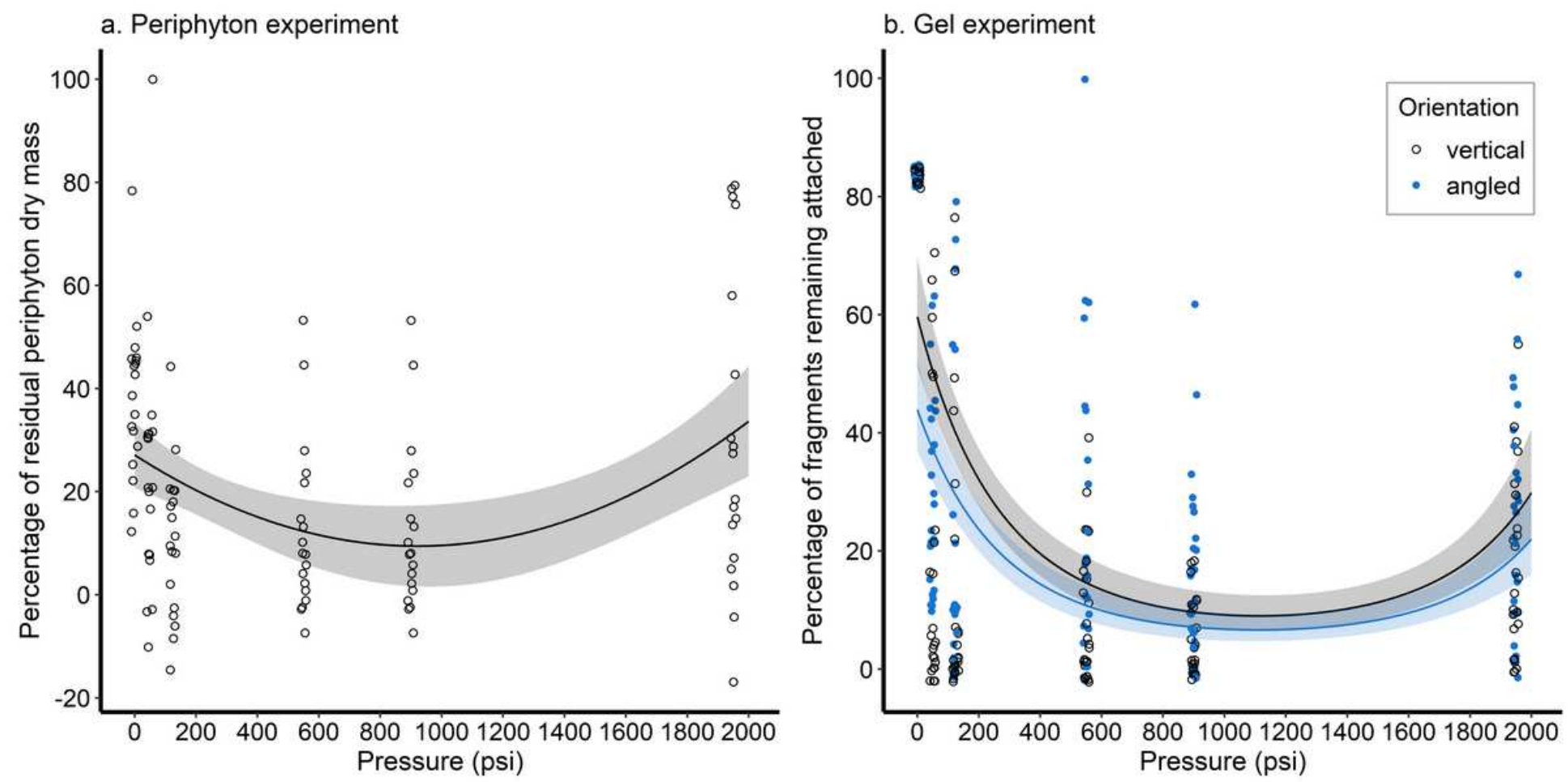

Figure 1

Relationship between amount of material remaining on surfaces and water pressure for a) naturally colonized and b) gel seeded experiments. Jittered points represent the observed data, solid lines and shaded areas indicate regression lines and $95 \%$ confidence bands, respectively. Open black circles correspond to tiles placed vertically or perpendicular to the ground, and blue dots to tiles placed at a $20^{\circ}$ angle to the ground. 
a. Hot water experiment

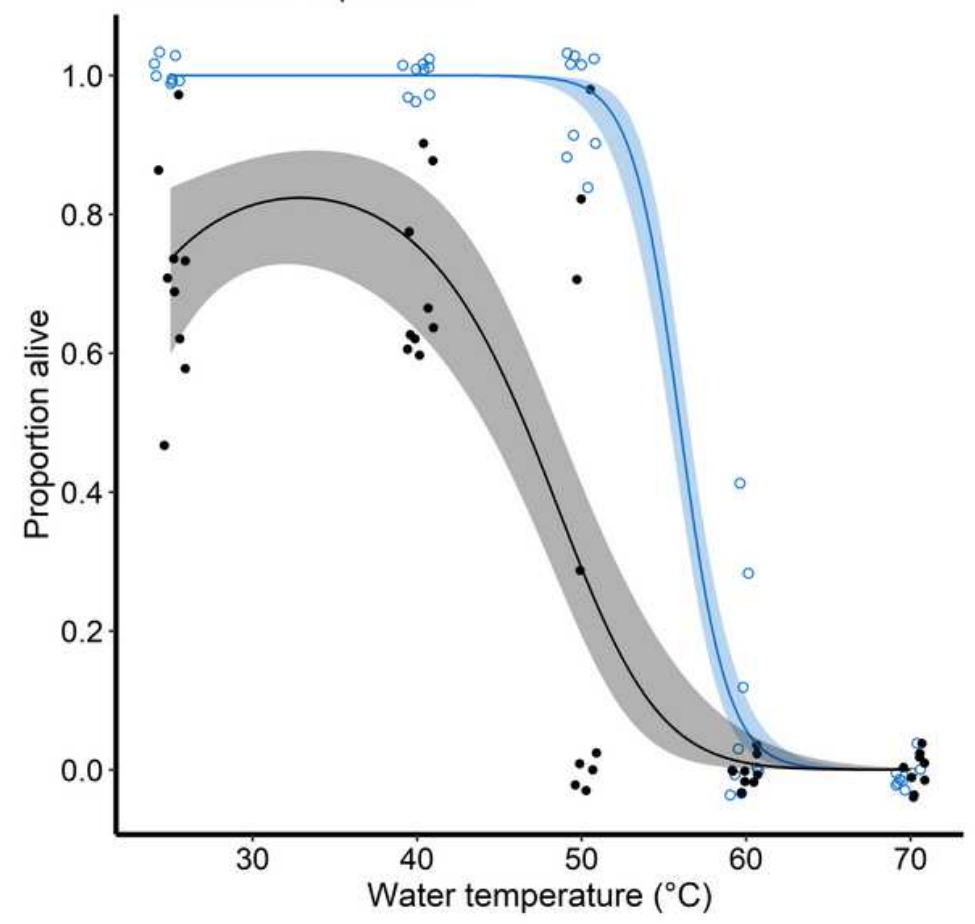

b. Air-drying experiment

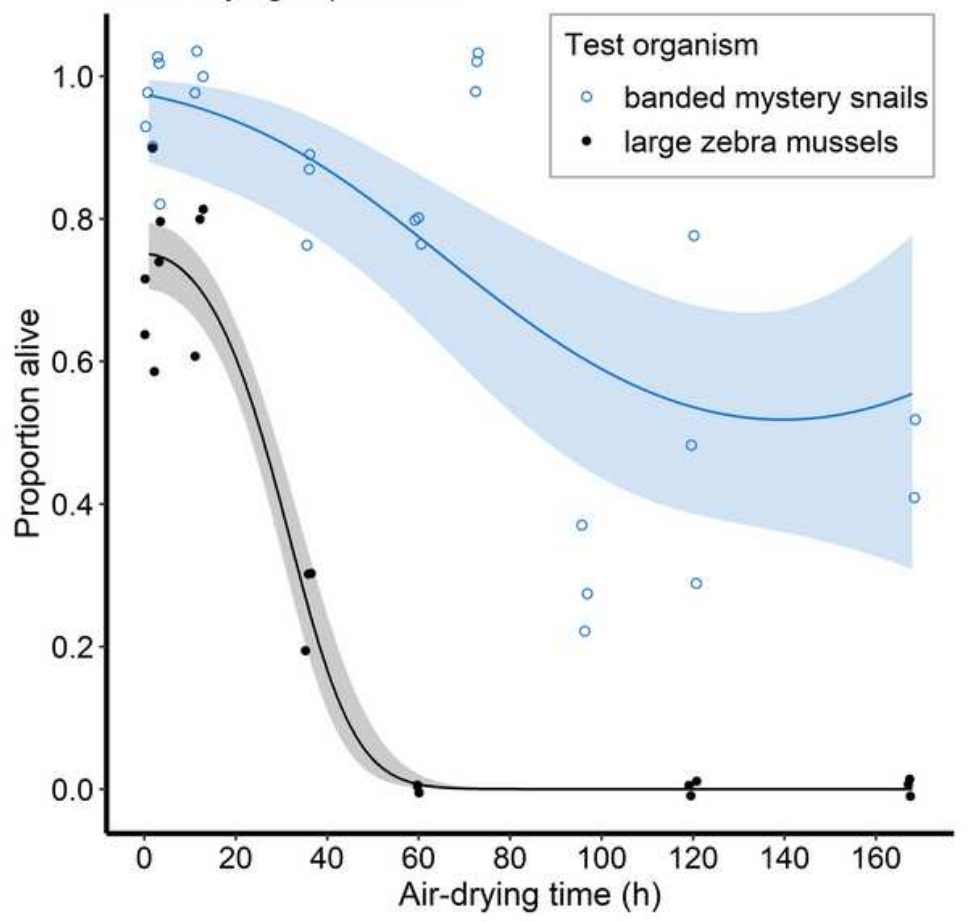

Figure 2

Relationship between banded mystery snail and large zebra mussel survival and a) hot water temperature (only results for $5 \mathrm{~s}$ immersion are shown) and b) air-drying duration. Open blue circles and black dots correspond to banded mystery snails and large zebra mussels, respectively.
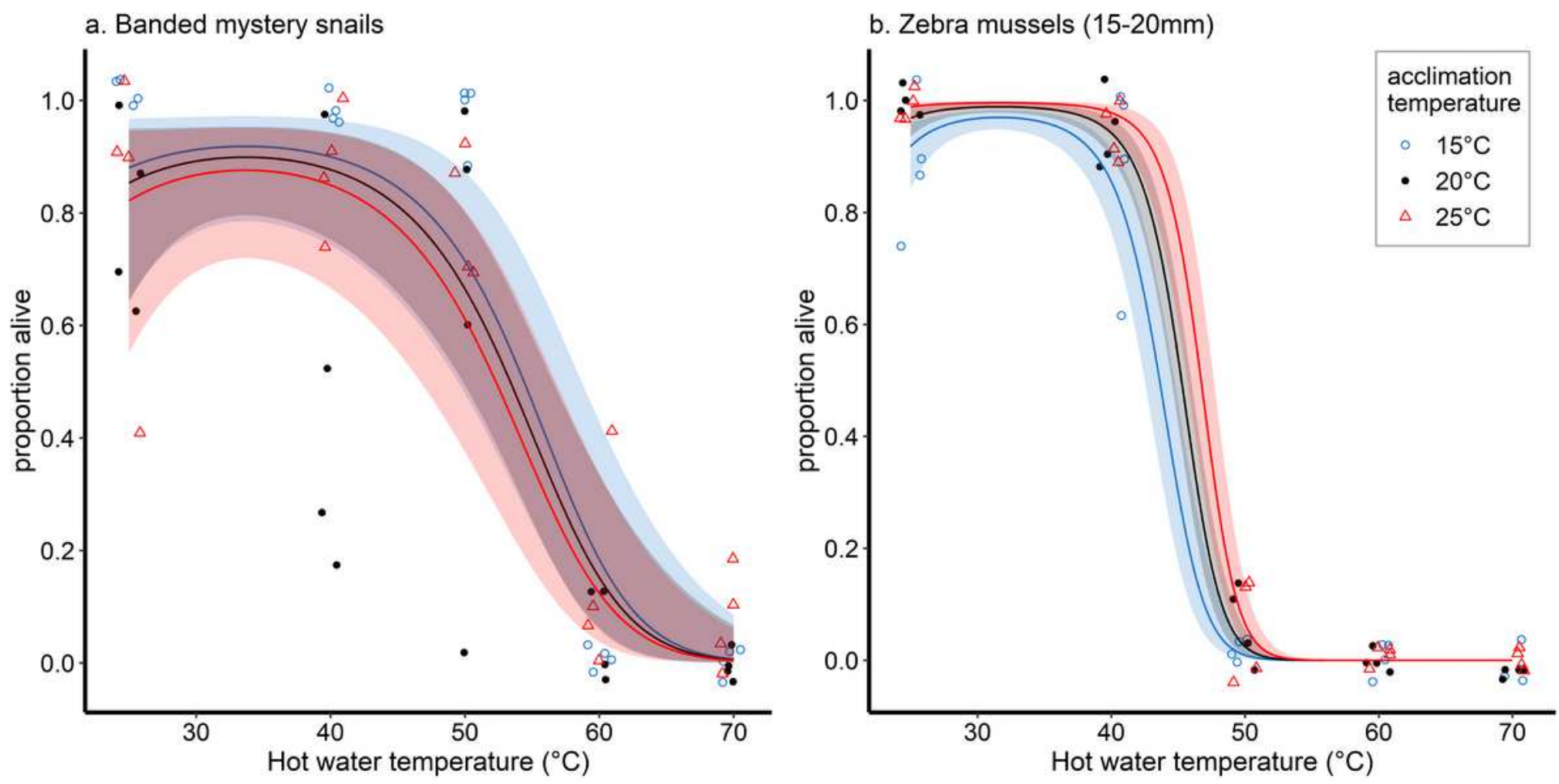

Figure 3 
Relationship between a) banded mystery snail and b) zebra mussel survival and hot water temperature at three acclimation temperatures. Open blue circles, black dots, red triangles correspond to acclimation at $15^{\circ} \mathrm{C}, 20^{\circ} \mathrm{C}$, and $25^{\circ} \mathrm{C}$, respectively.
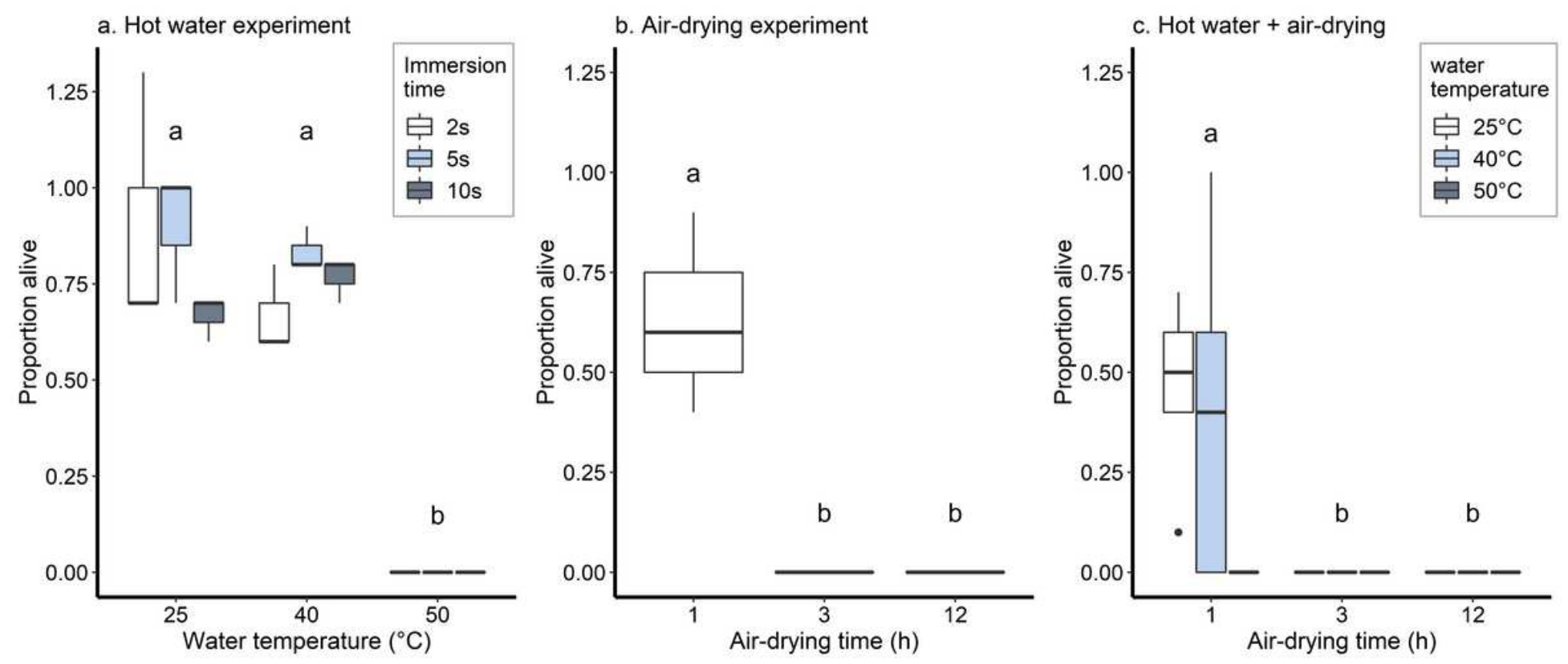

\section{Figure 4}

Spiny waterflea survival at different a) immersion temperatures, b) air-drying durations, and c) combined temperature plus air-drying. Groups sharing the same letter indicators were not significantly different from one another based on pairwise Tukey HSD test. White, light blue, and dark grey boxes correspond to immersion durations of $2 \mathrm{~s}, 5 \mathrm{~s}$, and $10 \mathrm{~s}$, respectively, in panel a, and to water temperatures of $25^{\circ} \mathrm{C}, 40^{\circ} \mathrm{C}$, and $50^{\circ} \mathrm{C}$ in panel $\mathrm{C}$. 

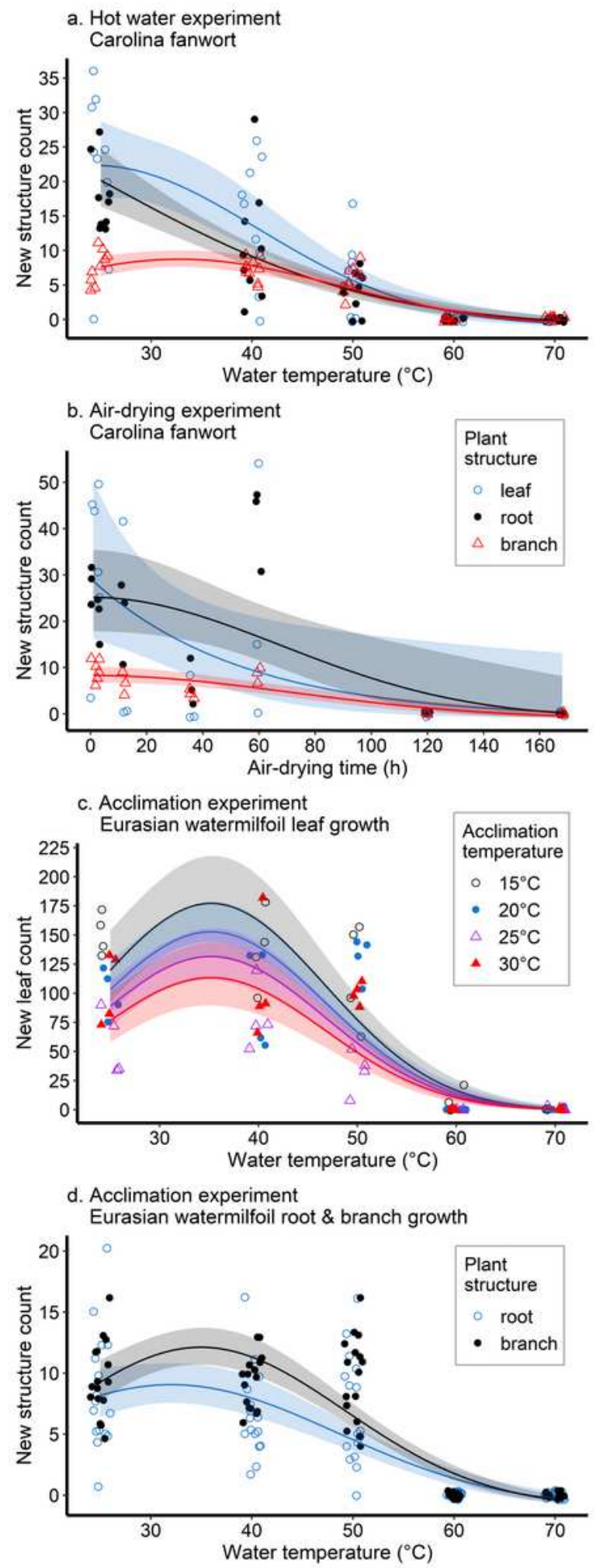

\section{Figure 5}

Relationship between new structure growth after 4 weeks (or 3 weeks for acclimation experiment) and a) temperature, b) air-drying, c) and d) temperature following acclimation for the most resistant macrophyte species within each experiment type. Panels $a$ and $b$ (results for Carolina fanwort): open blue circles number of leaves, black dots - number of roots, and red triangles - number of branches. Panel c (acclimation experiment results for Eurasian watermilfoil): open black circle - acclimation at $15^{\circ} \mathrm{C}$, blue 
dot - at $20^{\circ} \mathrm{C}$, open purple triangle - at $25^{\circ} \mathrm{C}$, and filled red triangle - at $30^{\circ} \mathrm{C}$. Panel d: open blue circles number of roots, and black dots - number of branches.

\begin{tabular}{|c|c|c|}
\hline GOOD & BETTER & BEST \\
\hline \multirow{4}{*}{$\begin{array}{l}\text { - Some form of decontamination } \\
\text { rather than none, e.g.: } \\
\text { - Manually removing debris } \\
\text { and biological material, } \\
\text { - Rinsing with water at } \\
\geq 50^{\circ} \mathrm{C}, \\
\text { - Air-drying for } 2 \text { to } 7 \text { days, } \\
\text { - Pressure-washing at } 250 \text { psi }\end{array}$} & \multirow{4}{*}{$\begin{array}{l}\text { - Applying more than one } \\
\text { previously listed method, or } \\
\text { - Using rigorous conditions, e.g.: } \\
\text { - Rinsing or immersion using } \\
\text { water at }>60^{\circ} \mathrm{C} \text {, } \\
\text { - Air-drying for } 7 \text { days, } \\
\text { - Pressure-washing at } 900 \text { to } \\
1200 \text { psi }\end{array}$} & $\begin{array}{l}\text { - Sequential application of multiple } \\
\text { methods, e.g.: } \\
\begin{array}{|c|}1 \text {. Visual inspection and } \\
\text { manual removal of biological } \\
\text { material, debris and mud. }\end{array}\end{array}$ \\
\hline & & $\begin{array}{l}\downarrow \\
\text { 2. Pressure-washing at } \\
\text { approximately } 900 \text { to } 1200 \mathrm{psi} \\
\text { to remove large invertebrates, } \\
\text { plant fragments and mud. }\end{array}$ \\
\hline & & $\begin{array}{l}\text { 3. Use of hot water at } 50^{\circ} \mathrm{C} \text { to } \\
60^{\circ} \mathrm{C} \text { to eliminate smaller } \\
\text { invertebrates and plant material } \\
\text { (rinsing or immersion). }\end{array}$ \\
\hline & & 4. Air-drying for $\geq 4$ days \\
\hline
\end{tabular}

Figure 6

Potential approaches to the implementation of decontamination methods with good, better, and best efficacy in reducing the number of viable specimens of aquatic invasive species.

\section{Supplementary Files}

This is a list of supplementary files associated with this preprint. Click to download.

- Table1.pdf

- Table2.pdf

- Table3.pdf

- Supplementarylnfo1additionalfigures.pdf

- Supplementarylnfo2modelselection.pdf

- Supplementarylnfo3statisticalresults.pdf 